\title{
APLICACIÓN DE LAS ANTOCIANINAS OBTENIDAS A PARTIR DE Zea mays L. (MAÍZ MORADO) COMO AGENTES INHIBIDORES DE LA AGREGACIÓN DE LOS PÉPTIDOS AMILOIDE Y TIPO AMILOIDE (TRIPSINA AGREGADA)
}

\author{
César A. Zaa ${ }^{* a}$, Fernando Retuerto Prieto ${ }^{\mathrm{a}}$, Álvaro J. Marcelo ${ }^{\mathrm{b}}$
}

\begin{abstract}
RESUMEN
El $\beta$-amiloide $(A \beta)$ es un péptido tóxico que posee una alta propensión a la agregación, y a menudo se encuentra presente en el cerebro de los pacientes con la enfermedad de Alzheimer (EA). Los compuestos bioactivos de plantas medicinales con propiedades neuroprotectoras, son agentes de especial interés en la protección contra formas tóxicas del péptido A $\beta$. En el presente trabajo evaluamos la capacidad antiagregante/desagregante de agregados amiloides y derivados amiloides in vitro por parte de las antocianinas de Zea mays L. (maíz morado). Utilizando el método de $\mathrm{pH}$ diferencial, cuantificamos el contenido de antocianinas totales. Con ayuda de las lecturas espectrofotométricas de los complejos proteína tipo amiloideRojo Congo y A $\beta$-Rojo Congo, evaluamos los efectos de antiagregación y desagregación por parte de las antocianinas sobre los péptidos amiloide y derivados amiloide. Los resultados obtenidos evidencian una significativa actividad de capacidad antiagregante y desagregante por parte de las antocianinas (33,54 y 26,63\%, respectivamente), la cual es dependiente de concentración. Además, las concentraciones de antocianinas encontradas de 32,95 y 280,69 $\mathrm{mg} / \mathrm{L}$ (en medio acuoso y metanólico acídico respectivamente), han sido comparadas con antocianinas y polifenoles de distinta fuente. Los resultados obtenidos son alentadores para continuar evaluando a las antocianinas como potenciales agentes biológicos.
\end{abstract}

Palabras clave: Zea mays L., maíz morado, antocianinas, amiloide, neuroprotección.

\footnotetext{
a Facultad de Ciencias Biológicas, Universidad Nacional Mayor de San Marcos, Av. Universitaria s/n., Lima 01, Perú, *alcesarzl@gmail.com

b Facultad de Ciencias Naturales y Matemática, Universidad Nacional Federico Villarreal. Jr. Río Chepén 290, El Agustino, Lima 01, Perú.
} 


\title{
APPLICATION OF ANTHOCYANINS OBTAINED FROM Zea mays L. (PURPLE CORN) AS INHIBITING AGENTS OF AGGREGATION OF AMYLOID AND AMYLOID-TYPE PEPTIDES (AGGREGRATED TRYPSIN)
}

\begin{abstract}
$\beta$-Amyloid $(A \beta)$ is a toxic peptide that has a high propensity for aggregation, and it is often present in the brains of patients with Alzheimer's disease (AD). Bioactive compounds from medicinal plants with neuroprotective properties are of interest in protecting against toxic forms of the $\mathrm{A} \beta$ peptide. In the present work, we evaluate the in vitro antiaggregant / disaggregating capacity of amyloid and amyloid-type aggregates by the anthocyanins of Zea mays L. (purple corn). Using the differential $\mathrm{pH}$ method, we quantified the total anthocyanin content. With the help of spectrophotometric readings of the amyloid-like protein-Congo Red and A $\beta$-Congo Red complexes, we evaluated the antiaggregation and disaggregation effects of anthocyanins on amyloid peptides and amyloid derivatives. The results showed a significant activity of antiaggregant / disaggregating capacity by anthocyanins, (33.54 and $26.63 \%$, respectively) which was dependent on the concentration. In addition, the anthocyanin concentrations found of 32.95 and $280.69 \mathrm{mg} / \mathrm{L}$ (in aqueous and acidic methanolic medium, respectively), have been compared with anthocyanins and polyphenols from different sources. The results obtained are encouraging to continue evaluating anthocyanins as potential biological agents.
\end{abstract}

Key words: Zea mays L., purple corn, anthocyanins, amyloid, neuroprotection.

\section{INTRODUCCIÓN}

El $\beta$-amiloide (A $\beta$ ) es un péptido de 38 a 42 aminoácidos, siendo el de 42 aminoácidos (A $\beta 1$ 42) el más común, que llega a ser la forma más neurotóxica e hidrofóbica con propensión a la agregación en el hipocampo y las regiones corticales de los pacientes con la enfermedad de Alzheimer (EA). Los estudios de la cinética de formación de fibrillas de $A \beta$ han demostrado que el tipo $A \beta 1-42$ forma fibrillas significativamente más rápido que el tipo A $\beta 1-40$. Además, los tratamientos que reducen los niveles de $\mathrm{A} \beta 1-42$ se correlacionan con una disminución del riesgo de la EA. El péptido $A \beta$ deriva de la escisión proteolítica de una glucoproteína llamada proteína precursora amiloide (PPA). La glicoproteína de membrana tipo 1 PPA juega un papel importante en una variedad de actividades biológicas ${ }^{1}$.

Los radicales libres contribuyen a la producción del péptido A $\beta$. Durante este proceso, el $\mathrm{A} \beta$ induce el estrés oxidativo asociado a la membrana neuronal, lo que aumenta la vulnerabilidad neuronal a la excitotoxicidad. Al aumentar la concentración de las especies reactivas del oxígeno (EROs), el tipo de fibrillas $A \beta$ puede provocar daños en el ADN nuclear y mitocondrial de las neuronas ${ }^{2}$. 
La estructura amiloide está compuesta por láminas beta cruzadas, conformando fibrillas de amiloide las cuales pueden estar asociadas con una serie de enfermedades neurodegenerativas. En estas fibrillas se incluyen a los péptidos $A \beta$ : dímeros, trímeros, tetrámeros (conocidos colectivamente como oligómeros), ligandos difusibles derivados del A $\beta$ (o ADDLs) y estructuras similares a un cordón de hasta $200 \mathrm{~nm}$ de longitud, llamadas protofibrillas ${ }^{3}$.

Los primeros estudios realizados sobre fibrillas amiloides mediante difracción de rayos X, revelaron que compartían una huella digital común, una hoja plegada en forma de $\beta$-cruzada. Esta evidencia luego se confirmó mediante un estudio de difracción de varias fibrillas amiloides ex vivo (evaluación hecha a partir de un tejido, todavía funcional, fuera del organismo) y sintéticas. El patrón de difracción de rayos X dada por las fibrillas amiloides, es " $\beta$-cruzada". Dicho patrón indica que estas moléculas fibrosas comparten una estructura central particular consistente de conformación de láminas $\beta$, en el cual la dirección de enlace de hidrógeno es paralela al eje de la fibra y las hebras $\beta$ son perpendiculares, muy parecidas a los peldaños de una escalera. En general, los modelos son de naturaleza $\beta$-cruzada y la conformación de la lámina $\beta$ forma el núcleo de la estructura. Los estudios de fibrillas formadas a partir del A $\beta$ de longitud completa han demostrado que el péptido se pliega en una estructura de curvatura $\beta$ que luego se asocia con otras moléculas para formar cadenas paralelas en la conformación de la estructura ${ }^{4}$.

En la figura 1 se muestra el modelo estructural para las fibrillas $A \beta 1-40$, consistente con las restricciones (entradas para los programas de generación de estructuras) de su dilucidación por resonancia magnética nuclear (RMN) en estado sólido sobre la conformación molecular y las distancias intermoleculares, e incorporando segmentos cortos de la estructura de una proteína en forma de cruz- $\beta$ común a todas las fibrillas amiloides ${ }^{11}$. La unidad $\beta$-cruzada es una estructura de doble capa, con 2 láminas $\beta$ paralelas formadas por los residuos 12-24 (aminoácidos Q15, L17, F19, A21, cintas naranjas) y 30-40 (aminoácidos I31, M35 y V39, cintas azules) las cuales son neutras y principalmente hidrófobas (posiciones no mostradas en la figura). Además, las cadenas laterales de A30, I32, L34, V36 y V40 (Figura 1b) forman una cara hidrófoba. 


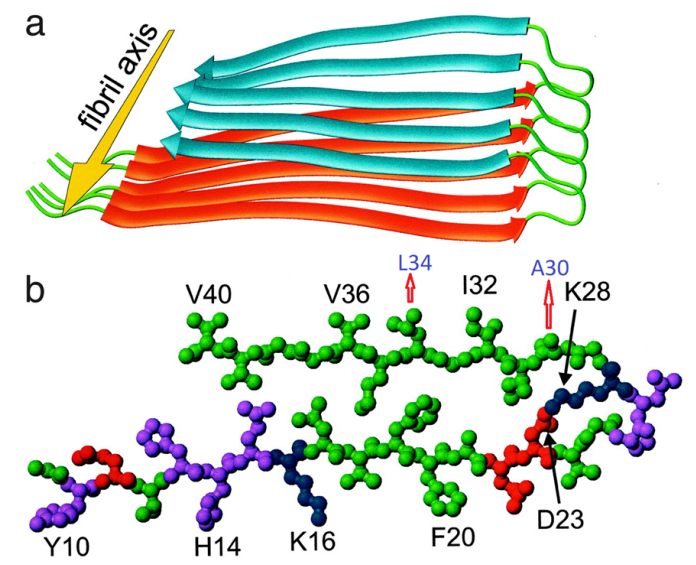

Figura 1. Modelo estructural para las fibrillas A $\beta$. (a) Representación esquemática de una sola capa molecular, o unidad $\beta$-cruzada. La flecha amarilla indica la dirección del eje largo de la fibrilla que coincide con la dirección de los enlaces de hidrógeno del esqueleto intermolecular. (b) Molécula central A $\beta 1-40$ del sistema de cinco cadenas de energía minimizada, vista hacia abajo del eje largo de la fibrilla4.

Los residuos están codificados por colores según sus cadenas laterales como hidrofóbico (verde), polar (magenta), carga positiva (azul) o carga negativa (rojo).

En la figura 2 se muestra la jerarquía de la estructura del péptido $\mathrm{A} \beta$ plegado en una estructura de lámina $\beta$ plegada desde protofilamenos a fibrillas amiloides ${ }^{5}$.

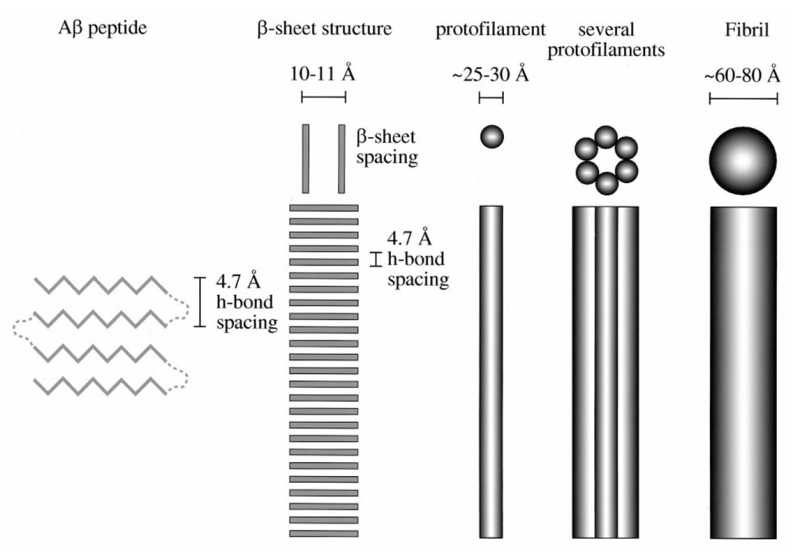

Figura 2. Representación de las fibrillas amiloides sintéticas obtenidas a partir de micrografía electrónica de péptido $\mathrm{A} \beta$ que muestra fibrillas largas, rectas y no ramificadas 5 . 
La extracción de los compuestos bioactivos (referidos principalmente a los polifenoles) con propiedades neuroprotectoras, a partir de plantas medicinales, es de gran interés debido a que dichos compuestos ejercen una protección contra las formas tóxicas del péptido $A \beta$. Por ejemplo, el metil cafeato, un éster fenólico, presente en diferentes plantas que son parte de la dieta humana como la albahaca, salvia, romero, o el té, es capaz de reconocer y unirse a oligómeros A $\beta 1-42$, mostrando actividad antiamiloidogénica ${ }^{6}$.

Recientes estudios han informado sobre el potencial de los antioxidantes en la inhibición de la deposición del péptido $\mathrm{A} \beta$ mediante ensayos in vitro e in vivo. Por ejemplo, los polifenoles del vino, la miricetina, morina, quercetina, kaempferol, $(+)$-catequina y $(-)$ - epicatequina, inhibieron la formación de las fibrillas $\mathrm{A} \beta$, así como su extensión7.

Varios agentes antioxidantes han demostrado ser neuroprotectores frente a la toxicidad inducida por el A $\beta$. La especie Zea mays L. es una variedad genética de maíz peruano, que presenta el colorante antocianina, el cual tiene aplicación en la industria farmacéutica y alimentaria. Las personas consumen este colorante principalmente en la bebida conocida como "chicha morada".

Entre los principales pigmentos del maíz morado se encuentran la cianidina 3,5-di-Oglucósido $(\mathrm{C} 3 \mathrm{G})$, la pelargonidina 3,5-di-O- glucósido, la peonidina así como sus respectivos derivados malonilos. La principal antocianina que se encuentra en mayor proporción en las plantas es la cianidina-3-glucósido, la cual se forma como consecuencia de un $\mathrm{pH}$ bajo9 .

La biosíntesis de la cianidina 3-O-glucósido se demostró mediante ingeniería genética en bacterias Escherichia coli. En la conversión de la leucoantocianidina (incolora) a antocianidina 3-glucósido (coloreada) participan al menos dos enzimas, antocianidina sintasa (ANS) y UDP-glucosa: flavonoide 3-O-glucosiltransferasa (3-GT). A pesar de la importancia de esta secuencia en la biosíntesis de las antocianinas, el mecanismo de reacción bioquímica no está definido. Los extractos crudos de Escherichia coli, que expresan ANS recombinantes de estas especies de plantas, y enzimas recombinantes purificadas de la petunia y el maíz, catalizaron la formación de antocianidina en presencia de iones ferrosos, 2-oxoglutarato y ascorbato. La formación in vitro de cianidina 3-glucósido (compuesto coloreado) a partir de la leucocianidina, se demostró utilizando la ANS de petunia y 3-GT ${ }^{10}$.

Se ha estudiado a las antocianinas debido a sus propiedades antioxidantes, antiinflamatorias y anticancerígenas, además, se ha demostrado que el uso de las antocianinas previene la obesidad, diabetes y enfermedades cardíacas, además, reduce el riesgo de diabetes, así como de trastornos de la función cognitiva ${ }^{11}$.

Se ha evidenciado que las antocianinas extraídas de la capa de semilla de la soja negra (Glycine $\max$ L.) tuvieron efecto neuroprotector en un modelo de toxicidad por privación de oxígenoglucosa y muerte celular inducida por glutamato en neuronas corticales primarias de rata. Este resultado podría estar relacionado a la inhibición del estrés oxidativo y la preservación del potencial de membrana mitocondrial ${ }^{12}$. 
En base a los antecedentes mencionados, en el presente trabajo se describe la cuantificación de antocianinas totales de Zea mays L. (maíz morado) y evaluación de la capacidad antiagregante/desagregante del péptido beta amiloide (A $\beta$ 1-42) y tipo amiloides (tripsina agregada) en modelos in vitro libres de células.

\section{PARTE EXPERIMENTAL}

\section{Material biológico}

Atomizado de Antocianinas extraídas de Zea mays L. (maíz morado), donado gentilmente por Sensient Natural Colors Perú S.A.C (antes Globenatural Colors S.A.C.).

\section{Material químico}

Tripsina liofilizada (Sigma-Aldrich), fragmento proteico $\beta$-amiloide A $\beta$ 1-42 (Sigma-Aldrich), Fluoruro de fenilmetilsulfonilo PMSF (Sigma-Aldrich), Rojo Congo, dimetilsulfóxido (DMSO) (Merck Millipore).

\section{Preparación de las muestras}

Los atomizados de antocianinas, altamente hidrofílicas, se disolvieron en agua ultrapura o sistema de buffer y se filtraron en filtros de $0.22 \mu \mathrm{m}$ previo a su uso. Las soluciones stocks preparadas se almacenaron en recipientes protegidos de la luz a $4{ }^{\circ} \mathrm{C}$ por un tiempo no mayor a 5 días.

\section{Determinación del contenido de antocianinas totales}

Absorbancia de $\mathrm{pH}$ diferencial

Los atomizados de antocianinas fueron utilizados para preparar soluciones acuosas y metanólicas de antocianinas. En la extracción acuosa se obtuvo una concentración de $1 \mathrm{mg} /$ $\mathrm{mL}$ en agua ultrapura. Para la extracción metanólica (acídica, con $\mathrm{HCl}$ al $1 \%$ ), se obtuvo una concentración de $5 \mathrm{mg} / \mathrm{mL}$. Los extractos se mantuvieron protegidos de la luz y fueron conservados a $4{ }^{\circ} \mathrm{C}$ por 24 horas. Luego se filtraron y conservaron a $4{ }^{\circ} \mathrm{C}$ hasta su uso.

En el procedimiento se utilizó 2 soluciones tampón: cloruro de potasio $(\mathrm{pH}=1 ; 0.025 \mathrm{M})$ y el acetato de sodio $(\mathrm{pH}=4.5 ; 0.4 \mathrm{M})$. Se diluyó $0,4 \mathrm{~mL}$ de cada extracto con 3,6 $\mathrm{mL}$ de cada tampón ( 2 muestras en tubos de $\mathrm{pH}=1 \mathrm{y} \mathrm{pH}=4.5)$.

Las absorbancias se midieron en el lector de microplaca Biotek Synergy a una longitud de onda de 510 y $700 \mathrm{~nm}$, con pH igual a 1 y 4.5, respectivamente. El contenido de antocianinas totales (CAT) se determinó usando el peso molecular y el coeficiente de extinción de la cianidina-3-glucósido (449.2 y 29600 respectivamente), y se expresó en mg de cianidina-3glucósido / L, de acuerdo con la siguiente ecuación ${ }^{13}$. 


\section{$A * \mathbf{P M}^{*} \mathbf{F D} * 1000$ \\ $\operatorname{CAT}(\mathrm{mg} / \mathrm{l})=\frac{\varepsilon^{*} \mathbf{l}}{}$}

Donde:

A: Absorbancia en $\mathrm{pH}=1(\lambda=510-700)$ y $\mathrm{pH}=4.5$

FD: Factor de dilución (10)

PM: peso molecular de la cianidina-3-glucósido $(449.2 \mathrm{~g} / \mathrm{mol})$

$\varepsilon$ : coeficiente de extinción molar de cianidina-3-glucósido $(26,900 \mathrm{~L} / \mathrm{mol} / \mathrm{cm})$

1: trayectoria óptica, $1 \mathrm{~cm}$

En el presente trabajo, se realizó una extracción de antocianinas totales y por el método de $\mathrm{pH}$ diferencial se expresaron como contenido de cianidina-3-glucósido (compuesto referencial de la principal antocianina en el maíz morado), tanto para las soluciones acuosas como alcohólicas.

\section{Ensayo de anti-agregación de proteína plegada tipo amiloide Medida de turbidimetría}

La estructura amiloide está compuesta por láminas beta cruzadas, conformadas por fibrillas de amiloide, las cuales pueden estar asociadas con una serie de enfermedades. En este trabajo, se evaluó el efecto inhibitorio de la formación de fibrillas tipo amiloides por parte de las antocianinas de Zea mays L.

Debido a que la agregación in vitro de proteínas solubles a menudo se puede evidenciar en condiciones suaves de desnaturalización, a alta temperatura, a valores de $\mathrm{pH}$ cercanos al punto isoeléctrico o en presencia de disolventes orgánicos polares, en el presente trabajo inducimos la agregación in vitro de la tripsina en etanol. Para evaluar la inhibición de la agregación, se indujo a la formación de fibrillas tipo amiloide por parte de la tripsina, mediante la coincubación con etanol acuoso, debido a que la desnaturalización inducida por el alcohol de la proteína nativa suele ir seguida de la inducción de una estructura de hélice $\alpha$ y una posterior transformación en una conformación de lámina $\beta$ predominante ${ }^{14}$.

Dichas fibrillas de tripsina, inducidas para su agregación en tipo amiloides, fueron inactivadas por el fluoruro de fenilmetilsulfonilo (PMSF) para evitar su autolisis, lo cual podría interferir en la formación de las fibrillas.

Se mezcló $50 \mu \mathrm{L}$ de PMSF $(50 \mathrm{mM})$ con $100 \mu \mathrm{L}$ de tripsina $(50 \mathrm{mg} / \mathrm{mL}$ en $\mathrm{HCl} 0.001 \mathrm{~N})$ y luego se adicionó $5 \mathrm{~mL}$ de buffer fosfato de potasio $(\mathrm{pH}=7)$. Se agitó la solución con miniimanes magnéticos por 20 minutos y se dejó en reposo por 1 hora a temperatura ambiente. Se filtró la solución y se completó a $10 \mathrm{~mL}$ con buffer fosfato de potasio $0.05 \mathrm{M}$.

La variación del coeficiente de extinción se controló a una longitud de onda igual a $350 \mathrm{~nm}$ usando el lector de microplaca Biotek 880. Para los ensayos se consideró lo siguiente: 1) Control, $100 \mu \mathrm{L}$ de la tripsina agregada (T); 2) $100 \mu \mathrm{L}$ tripsina y $90.91 \mu \mathrm{g} / \mathrm{mL}$ de antocianinas (ANT); 3) $100 \mu \mathrm{L}$ de la tripsina y $130.43 \mu \mathrm{g} / \mathrm{mL}$ ANT; 4) $100 \mu \mathrm{L}$ de la tripsina y $166.67 \mu \mathrm{g} /$ 
mL ANT; 5) $100 \mu \mathrm{L}$ de la tripsina y $200 \mu \mathrm{g} / \mathrm{mL}$ ANT; 6) $100 \mu \mathrm{L}$ de la tripsina y $230.77 \mu \mathrm{g} /$ mL ANT.

Los cambios en la turbidez se midieron a $24^{\circ} \mathrm{C}$ y a $\mathrm{pH}$ igual a 7.0 , en etanol al 55\% / tampón fosfato $10 \mathrm{mM}$, a una concentración de proteína de $0.15 \mathrm{mg} / \mathrm{mL}$ después de 24 horas de incubación. Los ensayos se llevaron a cabo después de la incubación de las fibrillas tipo amiloide por 10 minutos, con o sin presencia de distintas concentraciones de antocianinas.

\section{Ensayo de unión al Rojo Congo (RC). Inhibición de la agregación}

El ensayo de unión del colorante Rojo Congo a las fibrillas tipo amiloides formadas, se realizó por lecturas del espectro de absorción del Rojo Congo a las fibrillas formadas, a las longitudes de onda 340, 390, 450, 475, 595 y $650 \mathrm{~nm}$.

Debido a que las fibrillas amiloides de diversas proteínas tienen la capacidad de unirse a pequeñas moléculas planas, como por ejemplo el colorante específico de amiloide Rojo Congo, éste fue empleado para detectar la presencia de fibrillas tipo amiloides ${ }^{15}$. Por lo tanto, al evaluar el efecto inhibitorio de la formación de las antocianinas sobre las fibrillas amiloides, se observó una variación en el espectro de absorción del Rojo Congo, indicando estados de agregación / desagregación.

El colorante Rojo Congo fue preparado en $50 \mathrm{mM}$ de buffer fosfato salino con $150 \mathrm{mM}$ de $\mathrm{NaCl}$, para obtener una concentración final de $6.2 \mu \mathrm{M}$. Las proteínas agregadas se trabajaron a una concentración stock de $0.15 \mathrm{mg} / \mathrm{mL}$ en buffer fosfato $(\mathrm{pH}=7.0)$, en $55 \%$ etanol incubadas por 24 horas.

Para los ensayos se consideró lo siguiente: 1) $80 \mu \mathrm{L}$ de RC y $20 \mu \mathrm{L}$ tripsina (control); 2) $80 \mu \mathrm{L}$ de $\mathrm{RC}, 20 \mu \mathrm{L}$ tripsina y $90.91 \mu \mathrm{g} / \mathrm{mL}$ de antocianinas (ANT); 3) $80 \mu \mathrm{L}$ de RC, $20 \mu \mathrm{L}$ tripsina y $130.43 \mu \mathrm{g} / \mathrm{mL}$ ANT; 4) $80 \mu \mathrm{L}$ de RC, $20 \mu \mathrm{L}$ tripsina y $166.67 \mu \mathrm{g} / \mathrm{mL}$ ANT; 5) $80 \mu \mathrm{L}$ de $\mathrm{RC}, 20 \mu \mathrm{L}$ tripsina y $200 \mu \mathrm{g} / \mathrm{mL}$ ANT; 6) $80 \mu \mathrm{L}$ de RC, $20 \mu \mathrm{L}$ tripsina y $230.77 \mu \mathrm{g} / \mathrm{mL}$ ANT.

El porcentaje de inhibición se obtuvo comparando los promedios del pico máximo de absorbancia (a $475 \mathrm{~nm}$ ) de cada ensayo donde estaban presentes las antocianinas, el Rojo Congo y la tripsina agregada, respecto al control (solo tripsina agregada más Rojo Congo, sin antocianinas). Se expresó como porcentajes de reducción (inhibición) de la agregación.

\section{Ensayo de anti-agregación/desagregación de la proteína amiloide A $\beta 1-42$ Preparación del Rojo Congo (RC)}

Se preparó una solución stock de $7.18 \mathrm{mM}$ del colorante Rojo Congo en buffer PBS $(\mathrm{pH}=$ 7.4) y se filtró dos veces en papel whatman $\mathrm{N}^{\circ} 1$ para prevenir los grumos agregados. De esta solución stock se preparó la solución de trabajo $11 \mu \mathrm{M}$ y se determinó su máxima absorción en un barrido continuo de lecturas, en lector de microplaca Biotek Synergy LX, en el rango de $400-600 \mathrm{~nm}$, con intervalo de $10 \mathrm{~nm}$. Para conservar la estabilidad de las lecturas, se hicieron lecturas a las 4 y 24 horas de preparado. Se realizaron 3 repeticiones independientes 
para cada una de las longitudes de onda del barrido. La máxima absorción se encontró entre 490 y $510 \mathrm{~nm}$, con un pico máximo en $500 \mathrm{~nm}$.

\section{Preparación de los agregados beta amiloides (Aß1-42)}

El péptido A $\beta 1-42$ se disolvió en $\mathrm{DMSO} / \mathrm{NaOH} 0.1 \mathrm{mM}$. Luego se diluyó en fosfato de sodio acuoso $10 \mathrm{mM}$. Previo a los ensayos, los oligómeros se diluyeron en buffer PBS y centrifugaron a 2300 RPM por 90 minutos a temperatura ambiente. Finalmente, la mezcla se diluyó en PBS $40 \mathrm{mM}(0.02 \%$ azida de sodio). Las soluciones de trabajo se llevaron a una concentración final de $50 \mu \mathrm{M}$ y se dividieron en alícuotas para los ensayos de anti-agregación y desagregación con las distintas concentraciones de ANT.

\section{Ensayo de unión al Rojo Congo (RC)}

Los ensayos de unión de RC-A $\beta$ y RC-A $\beta$ con ANT (a distintas concentraciones), fueron llevados a cabo en el lector de microplacas Biotek Synergy LX mediante barrido de absorbancias en el rango de longitudes de onda de 400-600 nm con intervalos de $10 \mathrm{~nm}$. Se evaluó la antiagregación y desagregación del A $\beta 1-42$ por parte de las antocianinas. Como blanco se usó el PBS. Cada ensayo se realizó por triplicado, cuyos resultados de cada longitud de onda del barrido fueron promediados.

\section{Ensayo de inhibición de la agregación (antiagregación) del Aß1-42 - 24 horas}

Para evaluar la inhibición de los agregados fibrilares amiloides (A $\beta$ ) formados, se incubó 20 $\mu \mathrm{L}$ de los agregados $\mathrm{A} \beta$ solo o con distintas concentraciones de antocianinas $(47.62,90.91$, $130.43,166.67$ y $200 \mu \mathrm{g} / \mathrm{mL})$ por 24 horas a temperatura ambiente $\left(22^{\circ} \mathrm{C}\right)$. Luego, previo a la lectura, se agregó $80 \mu \mathrm{L}$ de Rojo Congo preparado anteriormente. Después de 20 minutos de reposo a temperatura ambiente, se realizaron las lecturas en lector de microplacas Biotek.

\section{Ensayo de inhibición de la agregación (antiagregación) del A $\beta 1-42$ por 20 horas}

El mismo experimento anterior se realizó para un tiempo de 20 horas a temperatura ambiente $\left(22{ }^{\circ} \mathrm{C}\right)$ para las soluciones que contenían solo agregados $\mathrm{A} \beta$ o aquellas con distintas concentraciones de antocianinas $(47.62,90.91,130.43,166.67$ y $200 \mu \mathrm{g} / \mathrm{mL})$.

\section{Ensayo de desagregación del Aß1-42 preformado por 24 horas}

Para evaluar la inhibición de los agregados fibrilares previamente formados, se incubó $20 \mu \mathrm{L}$ de los agregados $\mathrm{A} \beta$ por 24 horas a temperatura ambiente $\left(22^{\circ} \mathrm{C}\right)$. Luego, excepto al control, se adicionaron distintas concentraciones de antocianinas $(47.62,90.91,130.43,166.67$ y 200 $\mu \mathrm{g} / \mathrm{mL})$ e incubó por 4 horas adicionales a temperatura ambiente $\left(22^{\circ} \mathrm{C}\right)$. Previo a la lectura, se agregó $80 \mu \mathrm{L}$ de Rojo Congo. Después de 20 minutos de reposo y a temperatura ambiente, se realizaron las lecturas en lector de microplacas Biotek.

\section{Estadística}

Para el tratamiento de los datos empleó la hoja de cálculo Microsoft Excel 2010 y el software estadístico OriginLab - Microcal Origin 6.0. Los resultados se expresaron como el promedio y su desviación estándar para cada condición de tratamiento. La significación se determinó mediante un análisis de varianza de una vía (ANOVA). Se consideró un grado de significancia para $\mathrm{p}<0.05$. 


\section{RESULTADOS Y DISCUSIÓN}

\section{Contenido de antocianinas totales (CAT)}

En el presente trabajo, se determinó el contenido total de antocianinas monoméricas empleando el método de $\mathrm{pH}$ diferencial, el cual se basa en el cambio estructural del cromóforo de antocianinas entre $\mathrm{pH}$ de 1.0 y $4.5^{16}$. Se consideró como sustancia de referencia a la cianidina-3-glucósido debido a que esta sustancia es la más común en la naturaleza, con un coeficiente de extinción igual a $26900 \mathrm{~mol}^{-1} \cdot \mathrm{cm}^{-1}$ informado en la literatura para sistemas acuosos o alcohólicos. Si se desconoce la antocianina principal o su absortividad, es apropiado calcular el contenido total de antocianina monomérica utilizando la absortividad y el peso molecular de la cianidina-3-glucósido $\left(\varepsilon=26900 \mathrm{~L} \mathrm{~mol}^{-1} \cdot \mathrm{cm}^{-1}\right.$ y PM $=449.2 \mathrm{~g}$ / $\mathrm{mol})^{17}$.

De nuestros resultados obtenidos, el contenido de antocianinas monóméricas, en $\mathrm{mg} / \mathrm{L}$ equivalentes de la cianidina-3-glucósido, presenta un mayor valor en solución metanólica acídica en comparación con la solución acuosa (280.69 y $32.95 \mathrm{mg} / \mathrm{L}$, respectivamente) (tabla 1).

Tabla 1. Valores promedios del contenido de antocianinas monoméricas totales en los extractos acuoso y metanólico de atomizados de Zea mays L., variedad maíz morado.

\begin{tabular}{cc}
\hline Preparado & CAT $(\mathbf{m g} / \mathbf{L})^{*}$ \\
\hline Acuoso & 32,95 \\
Metanólico acídico & 280,69 \\
\hline
\end{tabular}

* Expresados como equivalentes de cianidina-3-glucósido (C3G).

\section{Ensayo de anti-agregación de proteína plegada tipo amiloide. Medida de turbidimetría}

Las antocianinas (ANT) fueron evaluadas para su actividad antiagregante contra la tripsina inducida a tipo amiloide. Se observa una reducción de la turbidimetría que es proporcional al incremento en la concentración de antocianinas, lo cual indicaría una inhibición de la agregación de la tripsina. Comparados con el control (tripsina agregada tipo amiloide: $\mathrm{T}$, sin la adición de las antocianinas), se observa reducciones significativas de la turbidez, del 45.38 y $66.61 \%$ a concentraciones de $200 \mu \mathrm{g} / \mathrm{mL}$ y $230.77 \mu \mathrm{g} / \mathrm{mL}$ de antocianas (figura 3, tabla 2).

Los porcentajes de reducción de la turbidez se obtuvieron comparando los valores promedios de las absorbancias de cada una de las soluciones que contiene la tripsina agregada (fibrillas tipo amiloide) con las distintas concentraciones de antocianinas respecto a la solución control que contiene solo tripsina agregadas ( $\sin$ antocianinas) ensayadas a $350 \mathrm{~nm}$. 

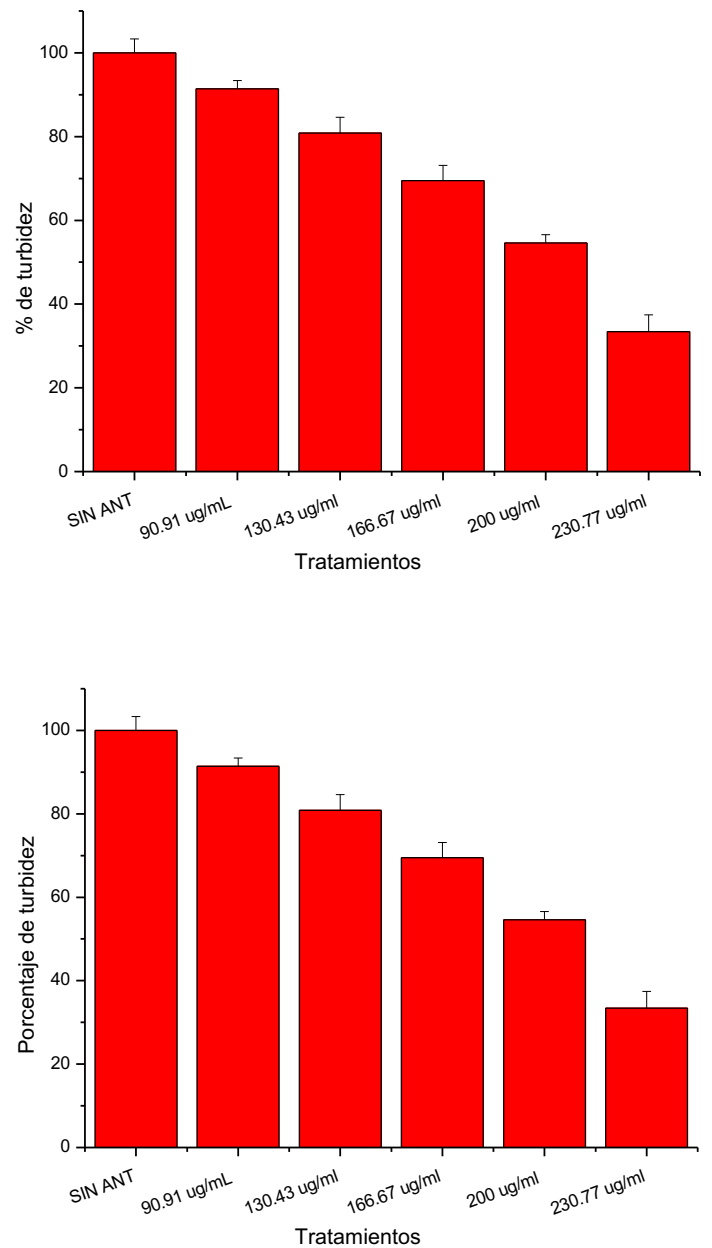

Figura 3. Variación de la turbidimetría en la formación de fibrillas tipo amiloide de las soluciones de tripsina $(0.15 \mathrm{mg} / \mathrm{mL})$ con distintas concentraciones de antocianinas $(90.91,130.43,166.67,200$ y $230.77 \mu \mathrm{g} / \mathrm{mL}$ ) y la solución control (tripsina sin antocianinas). 
Tabla 2. Porcentajes de inhibición de las antocianinas sobre la agregación de tripsina inducida a tipo amiloide (Medida de turbidimetría).

\begin{tabular}{ccc}
\hline Concentración de antocianinas $(\mu \mathrm{g} / \mathrm{L})$ & Absorbancia & \% Inhibición \\
\hline 0 & 0,55588 & 0 \\
90,91 & 0,50813 & 8,59 \\
130,43 & 0,44938 & 19,16 \\
166,67 & 0,38625 & 30,52 \\
200 & 0,30362 & 45,38 \\
230,77 & 0,18563 & 66,61 \\
\hline
\end{tabular}

\section{Ensayo de unión al Rojo Congo (RC). Inhibición de la agregación.}

Para la evaluación de la inhibición de la proteína agregada tipo amiloide, se consideró el pico máximo de absorbancia del complejo Tripsina -Rojo Congo (T-RC). Para este ensayo, la longitud de onda máxima fue de $475 \mathrm{~nm}$ (figura 4).

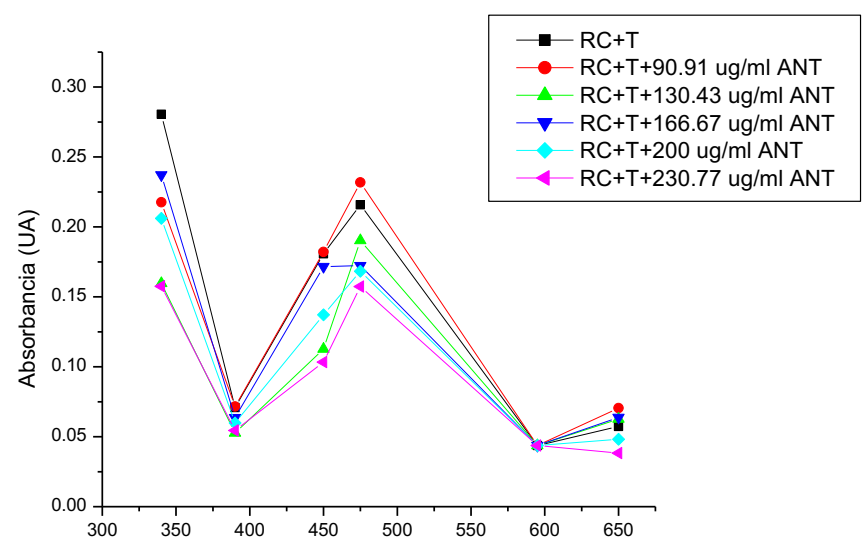

Figura 4. Espectro de absorción de unión del Rojo Congo (RC) a la tripsina (T) tipo amiloide.

Para la evaluación de la inhibición de la proteína agregada tipo amiloide, se consideró el pico máximo de absorbancia del complejo Tripsina -Rojo Congo (T-RC). Para este ensayo, la máxima absorción fue a $475 \mathrm{~nm}$. El tratamiento control (T-RC), muestra una absorbancia de 0.2158 , a partir del cual se evaluaron las distintas concentraciones de antocianinas. Excepto para la concentración más baja de antocianinas $(90.91 \mu \mathrm{g} / \mathrm{mL})$, la cual incrementa la absorción a 0.2318 (6.9 \% mayor a la concentración del control), las demás concentraciones crecientes reducen proporcionalmente las lecturas de absorbancia. Así, las reducciones en porcentajes son: $11.8,20.16,22.01$ y $27.11 \%$ (para las cuatro siguientes mayores concentraciones de $130.43,166.67,200$ y $230.77 \mu \mathrm{g} / \mathrm{mL}$, respectivamente) en comparación a los niveles basales del tratamiento control (T-RC) (figura 4). 


\section{Ensayos de anti-agregación/desagregación de la proteína amiloide Aß1-42}

Con el fin de determinar la actividad antiagregante y/o desagregante por parte de las antocianinas, evaluamos el efecto in vitro de las antocianinas sobre la agregación de la proteína amiloide $A \beta 1-42$ para 20 y 24 horas de incubación.

\section{Ensayo de inhibición de la agregación (antiagregación) del A $\mathbf{\beta 1 - 4 2}$ por 24 horas}

Para el ensayo de la inhibición de la agregación del A $\beta 1-42$ para 24 horas de co-incubación, se observa una tendencia de disminución de las absorbancias del complejo Rojo Congoagregados amiloides. Para la concentración más baja de antocianinas, $47.6190 \mu \mathrm{g} / \mathrm{mL}$, se tiene un porcentaje de inhibición del complejo Rojo Congo-agregados amiloides del $14.63 \%$. Así, para la mayor de concentración de antocianinas, $200 \mu \mathrm{g} / \mathrm{mL}$, el porcentaje de inhibición de la agregación aumenta significativamente a $33.54 \%$ (figura 5, tabla 3). Los porcentajes de reducción de la agregación se obtuvieron comparando los valores promedios de los picos máximos de absorbancias a $500 \mathrm{~nm}$ (indicado con un trazo vertical figura 5) de cada una de las soluciones con antocianinas con respecto al control (sin antocianinas, solo el péptido, el Rojo Congo, $\mathrm{A} \beta$ y RC).

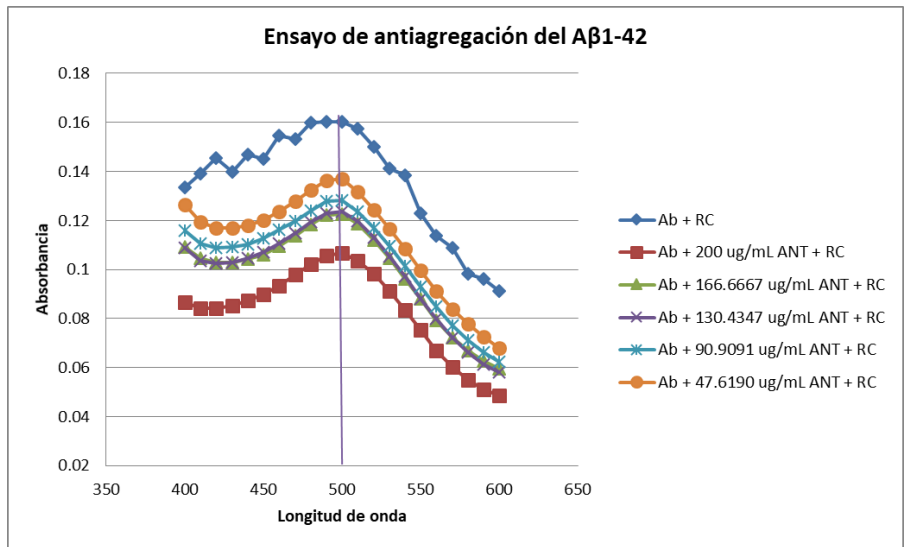

Figura 5. Efecto de la concentración de las antocianinas sobre la agregación del amiloide $\mathrm{A} \beta-42$ (Ab en el gráfico) y el control [amiloide (Ab) incubado con el Rojo Congo] para un tiempo de incubación de 24 horas.

Tabla 3. Porcentajes de inhibición de las antocianinas en el Ensayo de inhibición de la agregación del A $\beta 1-42$ (24 horas).

\begin{tabular}{ccc}
\hline Concentración de antocianinas $(\mu \mathrm{g} / \mathrm{mL})$ & Absorbancia & $\%$ Inhibición \\
\hline 0 & 0.1604 & 0 \\
47.62 & 0.1369 & 14.65 \\
90.91 & 0.1282 & 20.07 \\
130.43 & 0.1238 & 22.82 \\
166.67 & 0.1227 & 23.5 \\
200 & 0.1066 & 33.54 \\
\hline
\end{tabular}


Ensayo de inhibición de la agregación (antiagregación) del Aß1-42 durante 20 horas. Para el ensayo de la inhibición de la agregación del A $\beta 1-42$ para 20 horas de co-incubación, se observa una tendencia de disminución de las absorbancias del complejo Rojo Congoagregados amiloides. Así, para la mayor de concentración de antocianinas, $200 \mu \mathrm{g} / \mathrm{mL}$, el porcentaje de inhibición de la agregación aumenta significativamente al 30.74\%. (figura 6 , tabla 4). Los porcentajes de reducción de la agregación se obtuvieron comparando los valores promedios de los picos máximos de absorbancias a $500 \mathrm{~nm}$ (indicado con un trazo vertical, figura 6) de cada una de las soluciones con antocianinas respecto al control ( $\sin$ antocianinas, solo el péptido, el Rojo Congo, A $\beta$ y RC).

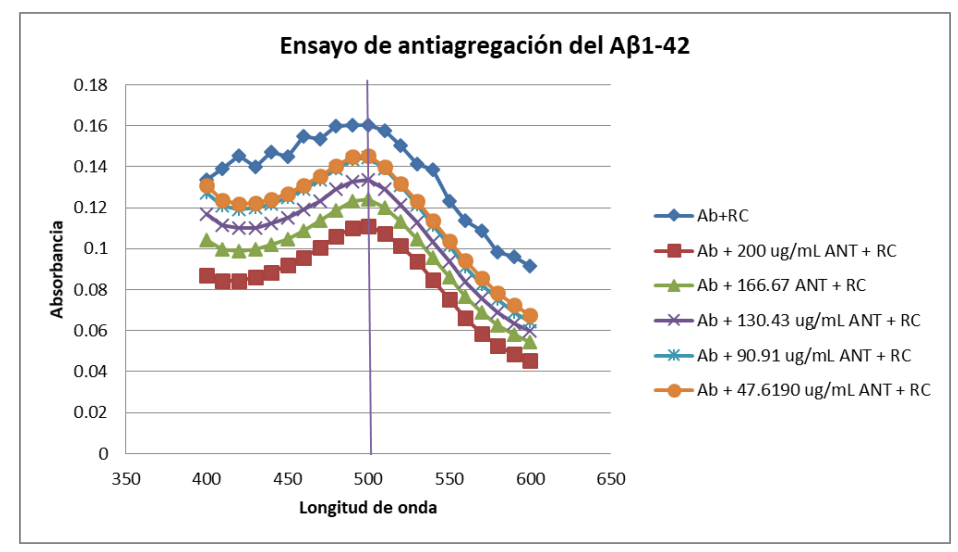

Figura 6. Efecto de la concentración de las antocianinas sobre la agregación del amiloide $(\mathrm{Ab})$ para un tiempo de incubación de 20 horas.

Tabla 4. Porcentajes de inhibición de las antocianinas en el ensayo de inhibición de la agregación del A $\beta 1-42$ durante 20 horas.

\begin{tabular}{ccc}
\hline Concentración de antocianinas $(\mu \mathrm{g} / \mathrm{mL})$ & Absorbancia & $\%$ Inhibición \\
\hline 0 & 0,1604 & 0 \\
47,62 & 0,1455 & 9,29 \\
90,91 & 0,1443 & 10,04 \\
130,43 & 0,1337 & 16,65 \\
166,67 & 0,1242 & 22,57 \\
200 & 0,1111 & 30,74 \\
\hline
\end{tabular}

\section{Ensayo de la desagregación del A $\beta 1-42$ preformado durante 24 horas.}

Para el ensayo del efecto de las antocianinas sobre la desagregación de las fibrillas A $\beta 1-42$ previamente formadas, se observa una tendencia de disminución de las absorbancias del complejo Rojo Congo-agregados amiloides. Además, se muestra que a una concentración de antocianinas mayor de $200 \mu \mathrm{g} / \mathrm{mL}$, el porcentaje de inhibición de la desagregación aumenta significativamente a $26.63 \%$ (figura 7, tabla 5). Los porcentajes de reducción de la desagregación se obtuvieron comparando los valores promedios de los picos máximos 
de absorbancias a $500 \mathrm{~nm}$ (indicado con un trazo vertical en la figura 7) de cada una de las soluciones con antocianinas respecto al control (sin antocianinas, solo el péptido, el Rojo Congo, $\mathrm{A} \beta$ y RC).

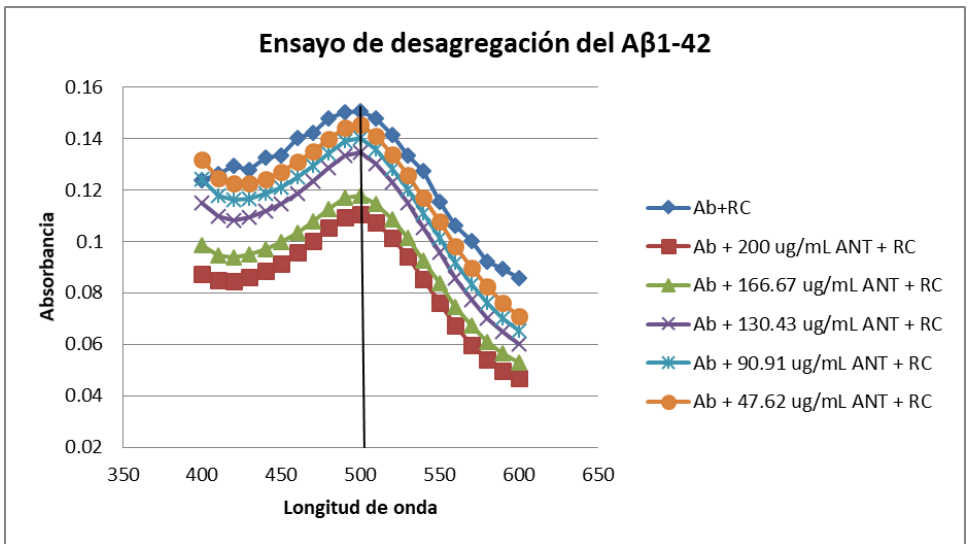

Figura 7. Efecto de la concentración de las antocianinas sobre la desagregación de las fibrillas amiloides [Ab] preformadas por 24 horas.

Tabla 5. Porcentajes de inhibición de las antocianinas en el ensayo de la desagregación del A $\beta 1-42$ preformado por 24 horas.

\begin{tabular}{ccc}
\hline Concentración de antocianinas $(\mu \mathrm{g} / \mathrm{mL})$ & Absorbancia & $\%$ Inhibición \\
\hline 0 & 0,1506 & 0 \\
47,62 & 0,1455 & 3,39 \\
90,91 & 0,14 & 7,04 \\
130,43 & 0,1345 & 10,69 \\
166,67 & 0,1177 & 21,85 \\
200 & 0,1105 & 26,63 \\
\hline
\end{tabular}

Se ha informado acerca de las concentraciones de antocianinas $(95-150 \mathrm{mg} / \mathrm{L})$ obtenidas a partir del maíz morado, según el tiempo y temperatura de extracción ${ }^{18}$. En comparación con estos valores, nuestros resultados del CAT son mayores para la extracción metanólica (280.9 $\mathrm{mg} / \mathrm{L})$.

El contenido de antocianinas, obtenido en la extracción metanólica acídica $(280.69 \mathrm{mg} / \mathrm{L})$, es mayor que la concentración de jugos y/o bebidas tal como el vino rojo, los jugos de fresa, arándano, incluso respecto a la sustancia estándar (cianidina-3-glucósido cloruro, 44.8 $\mathrm{mg} / \mathrm{L}$ ), pero es menor con respecto al contenido de antocianinas presente en la baya del saúco o la frambruesa ${ }^{13}$. A diferencia de nuestro trabajo, en este estudio comparativo se emplearon concentrados de jugos o extractos para sus mediciones. 
Las concentraciones obtenidas en este trabajo expresadas en mg de cianidina-3-glucósido por 100 g de muestra, fueron 3420.5703 y 2009.1649, para la extracción metanólica y acuosa, respectivamente. Por lo tanto, nuestros valores de CAT son mayores con respecto a los componentes de cuatro variedades ( 3 genotipos mejorados y uno comercial) evaluadas en un estudio aparte, que incluyen dos genotipos (KKU OP e híbrido KKU F1) cuyos mayores valores son 408.54 y $289.06 \mathrm{mg} / 100$ g equivalentes de cianidina-3-glucósido ${ }^{16}$.

Se ha informado que las concentraciones de antocianinas extraídas de las corontas de maíz morado a distintos tiempos y temperaturas fluctúan entre 11.567 y $37.127 \mathrm{mg} / \mathrm{g}$, correspondiendo sus valores más altos a las mayores temperaturas de extracción (cuyo mayor valor promedio es $32,737 \mathrm{mg} / \mathrm{g}$ de coronta a partir de los $\left.60^{\circ} \mathrm{C}\right)^{19}$. Estas concentraciones expresadas en $\mathrm{mg}$ de antocianinas por gramo de muestra, son de 34.23 y $20.09 \mathrm{mg} / \mathrm{g}$, para las extracciones metanólica y acuosa respectivamente, siendo comparativamente similares a sus máximos valores, o incluso mayores si se comparan con sus valores de extracción a temperatura ambiente $(16.279 \mathrm{mg} / \mathrm{g})$.

La medida de turbidimetría fue usada como un indicador del grado de agregación de la tripsina, la cual es una buena herramienta para evaluar la formación de agregados más grandes. Con respecto a un estudio similar empleando extractos de meliloto y menta, se muestra una tendencia notable en la reducción de la turbidimetría en una relación dependiente de concentración, para diluciones que van desde los 5x hasta los 160x (5 hasta 160 veces). Las diluciones se realizaron a partir de una solución de $55 \%$ etanol / $10 \mathrm{mM}$ buffer fosfato. Cuanto más concentrados eran los extractos, presentan una mayor reducción en la turbidimetría (casi completa en el caso del meliloto $)^{20}$. En nuestro trabajo, obtuvimos una disminución máxima de la turbidimetría de las fibrillas del $66.61 \%$ para una concentración de $230.77 \mu \mathrm{g} / \mathrm{mL}$ de antocianinas (concentración más alta en este estudio).

Asimismo, en estudios con extractos del clavo de olor se informa una significativa reducción de la turbidimetría (hasta el $10 \%$ ), y en los estudios con extractos de café existe una disminución centesimal (0.05) en el valor espectral del Rojo Congo, correspondiéndole un valor máximo de absorción, a partir del cual se evaluarían los extractos. En comparación con lo último mencionado, nuestros valores encontrados presentan mayores reducciones de unión al Rojo Congo (partiendo de un valor inicial de 0.2158 de absorbancia), lo cual se traduce en una mayor inhibición de la agregación. En otros trabajos realizados con extracto de semilla de pomelo y jugo de palta, se informan resultados similares a los encontrados en este trabajo en relación a la inhibición de la formación de fibrillas tipo amiloide ${ }^{21}$.

En un estudio de screening de diversas especias y hierbas, la menta, el pimiento rojo, la hierba buena y el tomillo, estos alimentos demostraron ser buenos inhibidores del polipéptido amiloide de los islotes (amilina), en su forma tóxica mediante el ensayo de unión a la tioflavina $\mathrm{T}$ la cual evalúa la fluorescencia proporcionalmente a la formación de agregados ${ }^{22}$. Sus valores de prevención de agregación fueron muy variados, variando desde 0 hasta más del $70 \%$, según la especie estudiada (de concentración única no mostrada). Comparado a nuestro resultado obtenido para la mayor concentración de antocianina empleada, se obtuvo un valor de $27.11 \%$ de reducción de la agregación (figura 4). 
En una aproximación sobre su capacidad de desagregación, las antocianinas muestran una significativa actividad desagregante (tabla 5, 26.63 \%) sobre las fibrillas amiloides (A $\beta 1-42$ ) preformadas en comparación a los efectos inhibitorios de su agregación informados para el extracto de café y jugo de granada ${ }^{23}$.

Además, se encontró que el extracto del aceite de la palma muestra una inhibición en la agregación del péptido $\mathrm{A} \beta 1-42$ dependiente de dosis, a una concentración de inhibición IC50 $=3.24 \mu \mathrm{g} / \mathrm{mL}^{24}$. Si bien sus proporciones de extracto para la lectura espectrofotométrica son distintas, nuestros resultados evaluados para el A $\beta 1-42$ evidencian una tendencia similar a la reducción en su agregación, dependiente de concentración. Recientemente, se están realizando estudios que proporcionan información a nivel molecular sobre cómo los polifenoles inhiben la formación de fibrillas $\mathrm{A} \beta$, conocimiento que podría ser útil para diseñar inhibidores del amiloide. En estudios realizados con los extractos de pétalos de rosa, hojas de uva, así como varias de sus fracciones, se ha evidenciado que estos extractos inhibieron significativamente el proceso de agregación de péptidos amiloides A $\beta 1-40$ y A $\beta 1-42$ incubados durante tres días ${ }^{25}$. Además, los fenoles presentes en los pétalos de rosa y hojas de uva desagregan hasta un $33 \%$ los agregados preformados del péptido $A \beta 1-42$. Si bien sus evaluaciones se basaron en espectros de fluorescencia del complejo de la tioflavina $T$ con el amiloide $A \beta 1-42$, nuestros resultados muestran una desagregación del $26.63 \%$.

\section{CONCLUSIONES}

En este trabajo se ha determinado la concentración de las antocianinas obtenidas a partir de la especie Zea mays L (maíz morado) y se ha evidenciado que estas antocianinas poseen una significativa actividad de capacidad antiagregante/desagregante para los modelos de agregación con proteínas agregadas tipo amiloide y el péptido amiloide A $\beta 1-42$, las cuales son dependientes de la concentración.

Los resultados obtenidos en los ensayos de la inhibición de la agregación evidenciaron: a) reducción de la turbidimetría de la proteína agregada tipo amiloide; b) inhibición de la proteína agregada tipo amiloide a partir de la absorbancia del complejo proteína-Rojo Congo; c) inhibición de la agregación del A $\beta 1-42$ durante 20 y 24 horas de incubación, mientras que en los ensayos de la desagregación de las fibrillas A $\beta 1-42$ previamente formadas, evidenciaron una disminución de las absorbancias del complejo Rojo Congo-agregados amiloides y la disminución de la agregación que fue proporcional al incremento en la concentración de antocianinas.

Los resultados encontrados son alentadores para seguir investigando a las antocianinas como potenciales agentes biológicos que eviten algunas enfermedades. 


\section{AGRADECIMIENTO}

Agradecemos gentilmente la empresa SENSIENT Colors (ex Globe Natural) por proporcionarnos los atomizados de antocianinas. A IBRO (International Brain Research Organization) por su apoyo económico para una estadía en el extranjero. El presente trabajo fue parte de la Tesis de la Maestría en Biología Molecular, desarrollada en la FCB-UNMSM, del autor principal.

\section{REFERENCIAS BIBLIOGRÁFICAS}

1. Bitan G, Kirkitadze MD, Lomakin A, Vollers SS, Benedek GB, Teplow DB. Amyloid $\beta$-protein $(A \beta)$ assembly: $A \beta 40$ and $A \beta 42$ oligomerize through distinct pathways. PNAS. 2003; 100 (1): 330-335.

2. Kruman II, Kumaravel TS, Lohani A, Pedersen WA, Cutler RG, Kruman Y, et al. Folic acid deficiency and homocysteine impair DNA repair in hippocampal neurons and sensitize them to amyloid toxicity in experimental models of Alzheimer's disease. $\mathrm{J}$ Neurosci. 2002; 22(5): 1752-1762.

3. Harper JD, Wong SS, Lieber CM, Lansbury PT. Observation of metastable Abeta amyloid protofibrils by atomic force microscopy. Chem Biol. 1997; 4(2): 119-125.

4. Petkova AT, Ishii Y, Balbach JJ, Antzutkin ON, Leapman RD, Delaglio F, et al. A structural model for Alzheimer's $\beta$-amyloid fibrils based on experimental constraints from solid state NMR. Proc Natl Acad Sci U S A. 2002; 24, 99(26): 16742-16747.

5. Serpell LC. Alzheimer's amyloid fibrils: structure and assembly. Biochim Biophys Acta. 2000; 1502(1): 16-30.

6. Airoldi C, Sironi E, Dias C, Marcelo F, Martins A, Rauter AP, et al. Natural Compounds Against Alzheimer's Disease: Molecular Recognition of A $\beta$ (1-42) Peptide by Salvia Sclareoides Extract and Its Major Component, Rosmarinic Acid, As Investigated by NMR. Chem Asian J. 2013; 8: 596-602.

7. Ono K, Yoshiike Y, Takashima A, Hasegawa K, Naiki H, Yamada M. Potent antiamyloidogenic and fibril-destabilizing effects of polyphenols in vitro: Implications for the prevention and therapeutics of Alzheimer's disease. J Neurochem. 2003; 87: 172181.

8. Lao F, Sigurdson GT, Giusti MM. Health Benefits of Purple Corn (Zea mays L.) Phenolic Compounds. Compr Rev Food Sci Food Saf. 2017; 16(2): 234-246.

9. Nakajima JI, Tanaka Y, Yamazaki M, Saito K., Reaction mechanism from leucoanthocyanidin to anthocyanidin 3-glucoside, a key reaction for coloring in anthocyanin biosynthesis. J Biol Chem. 2001; 276(28): 25797-25803.

10. Yan Y, Chemler J, Huang L, Martens S, Koffas MA. Metabolic engineering of anthocyanin biosynthesis in Escherichia coli". Appl Environ Microbiol. 2005. 71 (7): 3617-3623.

11. Tsuda T. Dietary anthocyanin-rich plants: biochemical basis and recent progress in health benefits studies. Mol Nutr Food Res. 2012, 56(1): 159-170.

12. Bhuiyan MI, Kim JY, Ha TJ, Kim SY, Cho KO. Anthocyanins Extracted from Black Soybean Seed Coat Protect Primary Cortical Neurons against in Vitro Ischemia. Biol Pharm Bull. 2012; 35(7): 999-1008. 
13. Lee J, Durst R, Wrolstad RE. Determination of Total Monomeric Anthocyanin Pigment Content of Fruit Juices, Beverages, Natural Colorants, and Wines by the $\mathrm{pH}$ Differential Method: Collaborative Study. J AOAC Int. 2005; 88(5): 1269-1278.

14. Kayser JJ, Arnold P, Steffen-Heins A, Schwarz K, Keppler JK. Functional ethanolinduced fibrils: Influence of solvents and temperature on amyloid-like aggregation of beta-lactoglobulin. J Food Eng. 2020; 270, 109764.

15. Espargaró A, Llabrés S, Saupe SJ, Curutchet C, Luque FJ, Sabaté R. On the Binding of Congo Red to Amyloid Fibrils. Angew Chem Int Ed. 2020; 59:1-5.

16. Sakunkan S, Surasak B, Bhornchai H. Anthocyanin content, total phenolic content, and antiradical capacity in different ear components of purple waxy corn at two maturation stages. Aust J Crop Sci. 2016; 10(5): 675-682.

17. HE, Azlan A, Tang ST, Lim SM. Anthocyanidins and anthocyanins: colored pigments as food, pharmaceutical ingredients, and the potential health benefits. Food Nutr Res. 2017; 61(1): 1-21.

18. Flores- Aguilar E, Flores-Rivera E. Estabilidad de Antocianinas, Fenoles totales y Capacidad Antioxidante de Bebidas de Maíz Morado (Zea mays L.) y Uña de Gato (Uncaria tomentosa sp). Inf Tecnol. 2018; 29(2): 175-184.

19. Gorriti Gutierrez A, Arroyo Acevedo J, Negron Ballarte L, Jurado Teixeira B, Purizaca Llajaruna H, Santiago Aquise I, et al. Antocianinas, fenoles totales y actividad antioxidante de las corontas del maíz morado (Zea mays L.): Método de extracción. Bol Latinoam Caribe Plantas Med Aromát. 2009; 8 (6): 509-518.

20. Kotormán M, Kelemen Z, Kasi P, Nemcsók J. Inhibition of the formation of amyloidlike fibrils using herbal extracts. Acta Biol Hung. 2018; 69(2): 125-134.

21. Kasi P, Kotormán M. Avocado Juice Prevents the Formation of Trypsin Amyloid-Like Fibrils in Aqueous Ethanol. Nat Prod Commun. 2019; 14(5): 1-5.

22. Fuentes AL, Hennessy K, Pascual J, Pepe N, Wang I, Santiago A. Identification of plant extracts that inhibit the formation of diabetes-linked IAPP Amyloid. J Herb Med. 2016; 6: $37-41$

23. Kasi P, Kotormán M. Among Commercially Available Fruit Juices, Pomegranate Is the Most Effective Inhibitor of PMS-Trypsin Amyloid-Like Fibrils Formation. Nat Prod Commun. 2019; 14(6): 1-5.

24. Weinberg RP, Koledova VV, Shin H, Park JH, Tan YA, Sinskey AJ, Sambanthamurthi R, Rha C. Oil Palm Phenolics Inhibit the In Vitro Aggregation of $\beta$-Amyloid Peptide into Oligomeric Complexes. Int J Alzheimer's Dis. 2018: 1-12.

25. Sharoyan SG, Antonyan AA, Harutyunyan HA, Mardanyan SS. Plant preparations suppress the aggregation of amyloid beta peptides and promote their disaggregation. Proc Yerevan State Univ. Chem Biol. 2015; 3: 39-46. 